THE U N I E R S I T Y O F M I C H I G A N COLLEGE OF ENGINEERING

Department of Aerospace Engineering

Gas Dynamics Laboratories

UNSTEADY FORCE AND PRESSURE MEASUREMENTS 8006

(Reprint)

William W. Willmarth

ORA Project 02:1490

under contract with:

DEPARTMENT OF THE NAVY

OFFICE OF NAVAL RESEARCH

CONTRACT NO. NO0014-67-A-0181-0015, NR 062-234 WASHINGTON, D.C.

administered through:

OFFICE OF RESEARCH ADMINISTRATION ANN ARBOR

September 1971

Approved for public release; distribution unlimited. 



\section{UNSTEADY FORCE AND PRESSURE MEASUREMENTS 8006}

\section{W. W. Willmarth}

Department of Aerospace Engineering

The University of Michigan, Ann Arbor, Michigan

\section{Introduction}

The solution to problems of the measurement of unsteady forces and pressures in fluid mechanics is an art similar to the innovative process required for design or invention. The solution process has the status of an art because the number of possible solutions to a given measurement problem is so large that one is required to base the solution process and selection of the measurement system upon one's taste and other abstract considerations like simplicity and beauty.

The art of successful experimental measurement requires that one have an accurate, intuitive knowledge of the pertinent physical phenomena so that this knowledge can be immediately used during the solution and experimental design process. Personally, I have found that the process of solution of a given problem requires the conception and mental testing of numerous iterative innovations of the original conception of the solution. For efficient and rapid solution it is also necessary to be thoroughly familiar with a wide class of existing experimental instruments and apparatus.

In this review various aspects of the general problem of unsteady pressure and force measurement are described, and a number of examples of solutions to various force- and pressure-measurement problems are outlined. The examples are intended to illustrate the application of significant general principles to the solution of these experimental problems and to show how the nature of the measurement problem can affect the solution. The examples are based primarily upon the author's experience. It has not been possible to present a complete coverage of the instruments and published work of the many very capable people in the field.

\section{General Considerations}

2.1 A comparison of unsteady force and pressure measurements.-The measurements of either unsteady forces or pressures have very much in common. In most measurement schemes it is a force that is sensed, and in many cases the same sensor and signal-generation system can be used for either measurement. The only significant difference between force- and pressure-measurement systems is caused by the nature of the medium through which the force is transmitted to the sensor. The unsteady forces 
that are measured in fluid-mechanical problems are usually transmitted by a relatively massive solid body (an aerodynamic body, model, or portion of a model) that is in contact with the sensor. Unsteady pressure measurements, on the other hand, are made in the fluid, and it is usually the fluid medium itself that is in contact with the sensor. The nature of the mechanical coupling between the sensor and the medium in contact with the sensor is very different in the two cases.

When unsteady forces are measured, the sensor must be as rigid as possible in order that undesirable low-frequency signals are not generated by mechanical vibrations of the coupled system of sensor and massive forcetransmitting structure. The coupling problem is almost always the single factor that limits the system response at high frequencies. Examples, given later, show how the entire measurement scheme for unsteady forces is of ten controlled by the requirement of accurate measurements at high frequency.

Measurements of unsteady pressures can readily be made at frequencies one or more orders of magnitude greater than the upper frequency limit for unsteady forces. The fidelity of the response at high frequencies is increased because the mass of fluid that moves with the sensor as it detects a change in force (i.e., pressure) is ordinarily much smaller than the corresponding mass of moving solid matter involved in unsteady force measurements. Here we are not considering special situations of strong coupling between the exterior fluid and fluid in a confined volume that might contain a sensor (e.g., Helmholtz resonators, Hartmann whistles, organ pipes, and similar situations).

The density of liquids is roughly one-thousand times that of air and other common gases. When a transducer with very low moving mass that deflects appreciably under load must be used in a liquid, it will have a lower natural frequency than in a gas owing to the greater mass of liquid coupled to the transducer motion. For this reason one normally uses a transducer or transducer material that is very rigid for pressure measurements in a liquid.

2.2 Transducers.-Almost all modern measurements of unsteady forces or pressures are made using transducers that convert a force into an electrical signal. In this section various transducers of this type that are in use at present are described. Force transducers that do not produce an electrical output signal (for example, purely mechanical systems) will not be considered because they usually are not suitable for detailed measurement of rapidly varying forces.

There are two broad classifications of force transducers that produce an electrical signal of one form or another. The first type is a transducer in which the applied force produces a change (on the molecular level) of an electrical property of the material of which the transducer is constructed. The second type is a transducer in which a gross electrical parameter (resistance, inductance, or capacitance) of an associated electrical circuit is altered by the applied force. For want of better names these are called molecular transducers and parametric transducers, respectively. 
This classification is by no means complete. It does cover many of the more common unsteady force- and pressure-measuring schemes. Perusal of the Transducer Compendium (Minnar 1963) or the books by Neubert (1963) and Lion (1959) will reveal many novel schemes that we do not have space to discuss or classify.

2.3 Molecular force transducers.-Examples of force transducers that operate at the molecular level are piezo-electric materials, magneto-strictive materials, and strain gauges of both metal and strongly electro-strictive materials.

2.3.1 Piezo-electric materials.-Piezo-electric materials (see Cady 1946) are crystalline dielectrics in which the application of a stress causes a change in the internal dipole moments of the molecules of the crystal, resulting in the production of surface charges that can be detected by electronic devices. A material frequently used for this type of transducer is quartz. In the past few decades barium titanate ${ }^{1}$ and more recently the proprietary material lead zirconate-titanate (PZT-5A) ${ }^{1}$ have come into wide use in force-transducer applications. Both barium titanate and lead zirconate-titanate are really ferro-electric materials (see Feynman 1964 for a clear qualitative description of piezo- and ferro-electricity). In ferro-electric materials the application of a polarizing electric field when the temperature of the material is raised above the Curie temperature and then lowered results in a permanent dipole moment in the direction of the applied field. After polarization the material remains polarized in the direction of the applied field unless the temperature is again raised above the Curie temperature.

The ferro-electric materials in common use are ceramics, which can be molded and sintered to obtain convenient shapes. They can then be polarized in any desired direction using the surface-charge detection electrodes. The ceramic, ferro-electric transducer is of ten much more convenient than a transducer made from a piezo-electric crystal. The piezo-electric crystal must be carefully cut to the desired shape, taking into account the orientation of the crystal axes and the method of force application.

2.3.2 Magneto-strictive materials.-Certain ferro-magnetic materials have the property of magneto-striction (see Neubert 1963, Feynman 1964) in which the application of a stress changes the degree of magnetization of the material. The change in magnetization can be electronically detected by sensing the induced current in a coil of wire magnetically linked with the magneto-strictive material.

Two commonly used magneto-strictive materials are pure nickel and an alloy of nickel and iron (68 percent nickel). The magneto-strictive transducers are consequently very rigid, giving very small deflection under load. For this reason they are very desirable transducer materials for high frequencies and large pressure fluctuations. There are a number of practical

${ }^{1}$ Commercially available from the Piezoelectric Division of Clevite Corporation, Bedford, Ohio. 
considerations-for example, temperature sensitivity, nonlinearity, and longtime instability (see Lion 1959) - that make the use of these materials difficult for quantitative measurements. In fluid-dynamic measurements, magneto-strictive force or pressure transducers are not commonly used owing to the availability of stable ferro-electric ceramic materials that are nearly as rigid as nickel (the modulus of elasticity for lead zirconate-titanate, PZT-5A, is approximately one-third that of nickel).

2.3.3 Strain gauge.-An electrically conducting material will change in electrical resistance when it is strained. This effect can be used to make a strain gauge in which the conducting material can be intimately bonded to the surface of the medium whose strain is to be measured. See the books by Dean \& Douglas (1962) and Perry \& Lissner (1963) for complete, detailed information about strain gauges. Here we will only outline their nature and characteristics.

Strain-gauge materials in modern use include fine metal wires, etched metal foils, and certain proprietary semiconductor materials (usually single silicon crystals with additives). The resistance change of metallic materials is caused almost entirely by dimensional changes of the wire or foil and to a small extent by electro-striction. The resistance change of semiconductor materials is caused primarily by electro-striction in which the change in configuration of the crystal lattice causes a change in molecular structure and an accompanying change in conductivity. When subjected to the same strain, the change in conductivity of a semiconductor strain gauge is one or two orders of magnitude greater than that of a metallic strain gauge.

The increased strain sensitivity of semiconductor materials is unfortunately accompanied by severe resistance changes caused by their large temperature coefficient of resistance. A suitable temperature-compensation or control scheme is necessary in all cases in which accurate measurements are to be made with metal or semiconductor strain gauges; however, temperature compensation or control is much more difficult when semiconductor strain gauges are used.

2.4 Parametric force transducers.-Many of the more common parametric force transducers used in fluid mechanics can be grouped in three general categories in which magnetic flux linkage, electrical capacitance, or electrical resistance are changed by the application of a force. In all cases parametric force transducers require a careful mechanical design to control the motion caused by the force that is to be measured.

There are very many other schemes for parametric transducers that do not fall under the above classification because they employ additional physical principles (e.g., conduction in gases or liquids, optical systems including lasers or other light sources, and electro-kinetic effects). One can find in the books by Neubert (1963) and Lion (1959) examples of different parametric transducers that have been made. These more complicated schemes are not of ten used for unsteady force and pressure measurements. 
Parametric force transducers based upon a variation of magnetic flux linkage include those in which one or more coils of wire are used to generate an electro-motive force by motion in a pre-existing magnetic field, and others in which the coils are fixed and the pre-existing magnetic field may be steady or alternating. If the magnetic field is not alternating, the output depends upon the time derivative of the displacement caused by the force. The electrical output can be made proportional to the displacement caused by the force if a high-frequency alternating magnetic field is used. The force fluctuations can be made to cause amplitude or frequency modulation of the output signal from the coils.

A change in capacitance can also be used to detect a force that moves either the plates or the dielectric material of a capacitor. In this case the capacitance change can be made essentially linearly proportional to the displacement caused by the force. The transducer is of ten operated with a constant charge on the capacitor, and the output voltage is approximately linearly related to the force for small changes in capacitance. The output signal is not reliable at very low frequencies because charge fluctuations caused by leakage currents in the capacitor or connections to the input stage of the electronic circuitry produce spurious signals. Faithful response in static or very-low-frequency measurements can be obtained if a carrier system is used in which the capacitance fluctuations caused by the force are made to frequency- or amplitude-modulate a carrier wave.

Parametric force transducers based upon a change in resistance have extremely simple electronic detection schemes (for example, one uses either a constant-current or constant-voltage source to drive the resistor and detects the changes in voltage or current, respectively). Although the electronic system is simple, most transducers of this type suffer from poor response at high frequencies or from electrical noise, or both. The familiar carbon microphone is a case in point since the variations in resistance produced by variations in pressure also cause random changes in resistance that are thought to originate at the many points of contact between the granules of carbon. High-quality film potentiometers with low wiper noise are available. In this case the response at high frequencies will be poor owing to the inertia and variations in contact pressure of the wiper. As a result of the limitations caused by noise and poor frequency response one finds that the most versatile transducer for unsteady forces that depends upon variation in resistance is the strain gauge, a molecular transducer.

2.5 Frequency response and sensitivity. - In the design of an instrument to measure unsteady forces or pressures the frequency response and sensitivity are important considerations that exert a strong influence on the design process. In almost all cases a linear relationship between the output signal and a single component of applied force or pressure is desired. A linear output can be obtained by operating the transducer over only a small part of its maximum usable range. The frequency response for more rapid 
pressure or force variations can then be described using the well-developed mathematical theory for vibrations of a linear system with a single degree of freedom.

There are numerous combinations and permutations of the spring, mass, and damping elements that can be involved in a particular discrete system. One can refer to the book by Housner \& Hudson (1950) for the vibration theory and for analysis of simple representative examples of vibration problems that arise in instrument design.

There are some useful generalizations that can be made about the related problems of frequency response and sensitivity that arise in the design of any instrument system. Vibrations of the transducer, and the fluid or solid in contact with it, at the natural frequency of the system represent excess energy stored in the system. This energy is accumulated over a period of time and this causes the transducer to produce signals that are not in phase with the pressure or force fluctuations that are to be measured. For example, when one measures a step increase in pressure or force, the transducer output signal will lag behind the input step but later will "overshoot" and oscillate about the final correct value of the signal.

There are two ways to obtain correct transducer-response signals without serious problems caused by instrument vibrations. The first and best method is to design the vibrating system formed by the measuring instrument and the fluid or solid matter to which it is coupled so that the natural frequency is very high compared with any frequency of interest in the pressure or force fluctuations that one is measuring. In the case of transient signals, for example, a step increase in pressure or force, the rise time of the output signal will be roughly one quarter of the natural period of vibration. The natural oscillations and overshoot phenomena that occur after the transducer responds to a transient signal can be reduced in magnitude by the incorporation of damping in the system or by passing the output signal through a low-pass electronic filter. Usually one should attempt to include the proper amount of damping in the transducer system itself because the energy stored in the vibrating system is thereby reduced and this reduces the possibility of overload of the transducer electronic circuitry. In other words, an undamped instrument may produce such largeamplitude oscillating signals (at the natural frequency) that the electronic detection circuit will operate in a nonlinear range and this causes distortion of the output signal (e.g., clipping in an extreme case). If clipping occurs the signal is nearly useless. One must also be sure that nonlinear distortion is not present in the signal before it is passed through a linear filter.

The other method that can be used to remove the effects of oscillations at the natural frequency is to use some type of compensation scheme. One can use a digital or analog computer to determine the input signal that caused the output signal that one observes. This compensation process is somewhat difficult because one must know the properties of the vibrating system formed by the transducer and the force- or pressure-transmitting medium to which it is coupled. Also, the scheme will work, even in principle, 
only for a linear system (since it amounts to solving an integral equation). Later in this paper two examples of such schemes will be discussed.

The sensitivity of a pressure- or force-measuring instrument is intimately related to its natural frequency. The natural frequency is approximately proportional to the inverse square root of the sensitivity, where the sensitivity is the ratio of the output signal to input force or pressure. Only a modest increase in natural frequency can be obtained at the expense of a considerable reduction in sensitivity. It is always desirable to have as great a sensitivity and natural frequency as possible. The correct procedure is to make sure that the natural frequency is no higher than required. For lightly damped systems one must choose the natural frequency approximately a factor of 10 higher than the highest frequency of interest in the measured quantity. In practice this may reduce the sensitivity considerably. If one can add damping to the instrument one can of ten tolerate a natural frequency only two or three times larger than the highest frequency of interest in the input signal. In a linear vibrating system, as one approaches resonance an appreciable shift in phase of the output signal relative to the input signal manifests itself long before the amplitude increase caused by oscillations near resonance becomes objectionable. One must be careful that this phase shift, which is still present in a damped system at the upper end of the frequency range of a transducer, does not affect the accuracy of the measurements.

Modern pressure and force measurements at low signal levels can be made over a greater frequency range than was possible in the past. This is a result of the improvements in sensitivity of electronic amplifiers during the last 15 years, which allow a greater reduction in transducer sensitivity (i.e., increase in natural frequency).

2.6 Electronics.-Remarkable developments in electronics technology occurred during the past two decades, and new developments are occurring at an accelerating pace. A description of new developments familiar to the author and applicable to the problems of unsteady force and pressure measurements is given below.

Electronic systems for experimental measurements have become extremely sophisticated. It is now possible, with the aid of a tape recorder and computer technology, to expose an instrument to the experimental environment and obtain a finished plot of the experimental data ready for publication. In the ordinary course of experimental research in which a few accurate measurements are made in a controlled situation, this degree of automation can only be approached after many months or even years of painstaking preliminary calculation, design, testing, and further refinement to correct inadvertent errors. Complete automation of an experiment should be approached with trepidation. Here we will discuss only the transducerelectronic systems used to produce an output signal that is related, in a known way, to the input quantity being measured.

Owing to the requirements of small physical size, high frequency response, and linearity, most force- or pressure-measuring transducers produce 
only a small electrical signal or a small change in an electrical parameter. The small transducer signals or parameter changes represent or cause small changes of electrical energy that must be faithfully amplified so that the energy in the amplified output signal is much larger than any undesired signals that may be encountered. For these reasons an amplifier is almost always a part of the electronic system.

There are many amplifiers available, and it is again not possible to discuss them in detail. Most modern amplifiers use transistors instead of vacuum electronic tubes. Transistors (of various types) are reliable, inexpensive, extremely small, and consume very little power. The small size of the transistor sometimes makes it possible to reduce the size of the force-transducing element because the transducer and amplifier (or perhaps only the first stage of the amplifier) can be placed adjacent to each other. Close spacing is desirable because low power signals from small transducers can be amplified at the transducer where they are generated without signal loss or electrical noise that would occur in a long cable leading from the transducer to the amplifier input.

Field-effect transistors with characteristics unobtainable with vacuum tubes (i.e., relatively low self-generated noise, good high-frequency response, and exceedingly high input impedance) have become available in recent years. When a field-effect transistor is used as the first stage of a transducer amplifier, its high input impedance can be a considerable advantage when used with small piezo-electric or capacitive type transducers. The high input impedance of a field-effect transistor reduces the load on the transducer thereby increasing the sensitivity or allowing one to use a smaller transducer (which produces a weaker signal) without compromising the instrument response at low frequencies.

Another significant development of the past decade is the invention of the monolithic integrated circuit, which combines numerous transistors, diodes, and resistors deposited in a thin film on a small chip of nonconducting material. Monolithic integrated-circuit amplifiers with a variety of input and output characteristics are commercially available on a single chip with an area of the order of $10 \mathrm{~mm}^{2}$. The chips are so small that the power and signal leads occupy the majority of the volume in the electronic package containing the chip.

Extremely versatile monolithic integrated-circuit amplifiers known as operational amplifiers have recently become available. The availability of inexpensive, relatively high quality, monolithic integrated-circuit operational amplifiers makes it possible to use the technology developed for analog computers to process transducer signals. One could actually (using analog-computer techniques) amplify and process the transducer signal within the pressure- or force-measuring instrument package.

A number of examples of schemes for signal processing to correct or reject erroneous transducer signals will be given later when examples of actual instruments are discussed. Here we will mention only the fact that one can readily add, subtract, and integrate signals. Direct differentiation with an 
operational amplifier is somewhat more difficult because the high-frequency components of the signal must be removed by a filter, to avoid noise generated at high frequencies by the operation of differentiation.

Within the past year, low-cost analog multipliers (with accuracy of the order of 1 percent) for use at high frequencies (negligible phase shift to 10 or $20 \mathrm{kHz}$ ) have become available. ${ }^{2}$ This development significantly extends the capabilities and versatility of on-line analog signal-processing, detection, and telemetry schemes.

Detailed information about the use of operational amplifiers for mathematical computations can be found in books on analog computation (see, for example, Johnson 1963). Because the field is rapidly developing, complete information regarding the use of operational amplifiers to amplify or otherwise process transducer signals does not (to the author's knowledge) reside in textbooks at present. For detailed information about the use of operational amplifiers for instrumentation, see Morrison (1964) and for methods using integrated-circuit operational amplifiers for transducer-signal processing, see the articles by Routh, Eimbinder, Seymour, Brown \& Krabbe (1969). More information about signal processing using operational amplifiers is contained in applications notes available from manufacturers such as Analog Devices, Burr Brown, Fairchild, Philbrick-Nexus, Zeltex, and many others. Detailed information about the characteristics of integratedcircuit operational amplifiers is available from major manufacturers, for example, Fairchild, Motorola, National Semi-conductor, Texas Instrument.

\section{Selected Examples of Measurement Systems for Unsteady Forces AND Torques}

There are numerous instruments available commercially for measuring unsteady forces. It is not intended to discuss or refer to commercial force transducers that usually can measure, very reliably, a single force component. Instead the examples selected for discussion are intended to illustrate a complete measurement system involving fundamental, versatile, and perhaps novel ideas or principles.

3.1 Two-component strain-gauge balance.-A very general principle for determining the lift and pitching moment of an aerodynamic body mounted on a sting is the use of strain gauges to measure the stress in the sting at two or three points. The sting may be considered as a cantilever beam so that the strain at the $i$ th strain-gauge location is (see Fig. 1a)

$$
\epsilon_{i}=\left(L x_{i}+M\right) / Q_{i}
$$

where $Q_{i}$ is the bending resistance at section $i$. From this it follows that the lift is given by the difference in the strain at sections 2 and 3 :

${ }^{2}$ Analog Devices, Motorola, and Zeltex are a few of the manufacturers of these multipliers. 


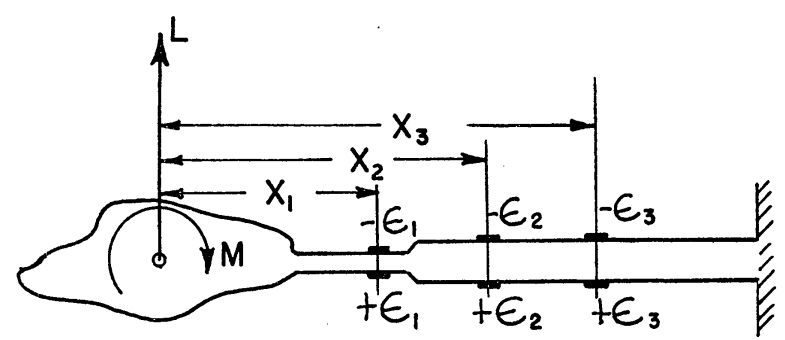

(a)

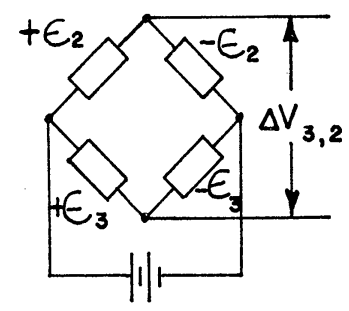

(b)

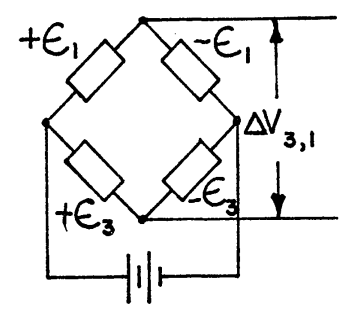

(c)

Figure 1. (a) Two-component strain-gauge balance. (b) Wheatstone bridge for lift signal (see Eq. 2). (c) Wheatstone bridge for moment signal (see Eq. 3).

$$
L=\left[Q_{2} /\left(x_{3}-x_{2}\right)\right]\left(\epsilon_{3}-\epsilon_{2}\right)
$$

An electrical signal proportional to the lift can be obtained with the Wheatstone bridge shown in Figure 1b. Note that the bridge arrangement provides temperature compensation (provided the temperature of the two gauges in each pair is the same).

The signals from the bridge of Figure $1 \mathrm{c}$ involving strain gauges 1 and 2 can be written

$$
\Delta V_{3,1} \propto\left[M\left(1 / Q_{3}-1 / Q_{1}\right)+L\left(x_{3} / Q_{3}-x_{1} / Q_{1}\right)\right]
$$

If we reduce the cross-sectional dimensions at station one so that $x_{3} Q_{1}=Q_{3} x_{1}$, the term involving $L$ vanishes and the voltage output of the bridge, Figure $1 \mathrm{c}$, is proportional to the moment $M$. This scheme for obtaining the steady moment was successfully used by many people; see an example in the paper of Reichardt \& Sattler (1962).

Another scheme to obtain the moment when $x_{3} Q_{1} \neq x_{1} Q_{3}$ is to use an online analog computer to subtract the term $L\left(x_{3} / Q_{3}-x_{1} / Q_{1}\right)$ from the voltage $\Delta V_{3,1}$ of Equation 3. This technique was used by Willmarth \& Enlow (1969). We also used semiconductor strain gauges, but discovered that the gauges had to be covered with a very thick layer of thermal insulation to avoid signals caused by temperature fluctuations due to the unsteady airflow over the semiconductor strain gauges. We used metal-foil strain gauges on the 


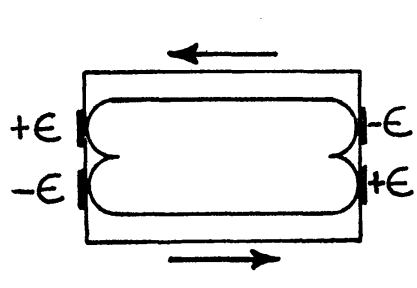

(a)

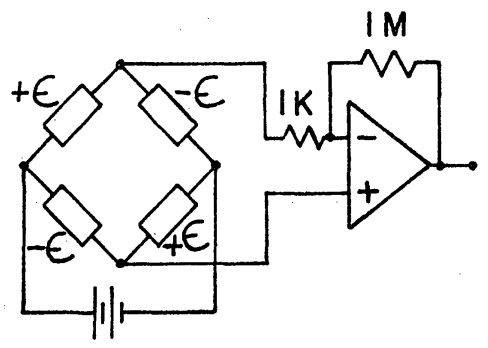

(b)

Figure 2. (a) Drag balance (Roos \& Willmarth 1968). (b) Wheatstone bridge and operational amplifier with gain of 1000 .

same balance and found that the thermally induced voltage fluctuations were a much smaller fraction of the lift and moment fluctuations. We now prefer to use metal-foil strain gauges in our strain-gauge balances. We have also found that with semiconductor strain gauges it is more difficult to obtain a reliable bond with the metal substrate.

The most difficult problem with a sting-type strain-gauge balance is obtaining a high natural frequency. It is usually necessary that the aerodynamic model that is mounted on the sting have very low mass in order that sufficient sensitivity remains when one must measure relatively high frequency fluctuations. In an investigation of lift fluctuations of a 2 -footdiameter sphere sting-mounted on a 2-inch-diameter tube with $\frac{1}{8}$ inch wall thickness (Willmarth \& Enlow 1969), it was necessary to form the sphere from a $\frac{3}{4}$-inch-thick styrofoam shell. The natural frrquency was still rather low, $36 \mathrm{~Hz}$, despite the low mass of the styrofoam sphere.

3.2 Strain-gauge drag balance.-A very simple strain-gauge drag balance (Roos \& Willmarth 1968) can be made from a block of metal that has been machined to provide parallelogram flexure elements that deflect when a drag force is applied (see Fig. 2). Small metal-foil strain gauges ${ }^{3}$ are mounted on the flexure elements. A full bridge provides maximum sensitivity and temperature compensation. The sensitivity of the balance was $2.5 \mathrm{mV} / \mathrm{lb}$ with a bridge drive voltage of $5 \mathrm{~V}$.

The drag balance was used to study the drag of a sphere in accelerated motion. The balance was inside the sphere, which was sting-mounted and towed through water. The strain gauges and leads were covered with a water-proof coating. ${ }^{4}$ In this application the drag balance also responds to the forces caused by acceleration of the sphere mass and the water trapped inside the sphere. The inertial-force signal was considerable and had to be removed. This was accomplished with an operational amplifier, which was

\footnotetext{
${ }^{3}$ Manufactured by Micro-Measurements Inc., Romulus, Mich.

${ }^{4}$ Gagekote Number 5, W. T. Bean Co., Detroit, Mich.
} 
used to subtract a signal proportional to the acceleration from the dragbalance signal. The acceleration signal was obtained from a small straingauge accelerometer that we constructed using strain gauges mounted at the root of a cantilever beam fitted with a small mass of lead.

For all strain-gauge bridges and for the subtraction of the acceleration signal Philbrick PP85AU operational amplifiers were used.

A typical circuit that was used for an amplifier with a gain of 1000 is shown in Figure 2. The mass of the sphere and the water inside were such that with the drag balance a natural frequency of $31 \mathrm{~Hz}$ was obtained for oscillations in the drag-force direction.

3.3 Moment balance and vibration-compensation circuitry.-In the investigation of fluctuations of moment about the axis of an oscillating rightcircular cylinder (Willmarth, Hawk, Galloway \& Roos 1967), a strain-gauge balance was constructed to measure the unsteady torque about the axis of rotation of the cylinder. The heart of the balance was the novel type of flexure pivot used to suspend the cylinder and allow free rotation so that torque could be measured with metal-foil strain gauges mounted on cantilever beams (see Fig. 3a). The idea for the flexure pivots was obtained from Eastman (1935). The pivots consist of two sets of three steel music wires. Each of the three wires lies in a plane making an angle of 120 degrees with the planes of the other two and passing through the axis of the pivot. The wires are staggered just enough to provide clearance at the point where they cross the axis. The flexure-pivot wires were assembled in a special jig and were silver soldered in holes drilled through cylindrical metal support members at each end. Axial tension was applied by means of an expansion-screw arrangement to lengthen the outer supporting cylinder. The flexure pivots were very satisfactory. It was possible to detect (without interaction) a moment of $0.01 \mathrm{ft}-\mathrm{lb}$ when a force of $26 \mathrm{lb}$ was applied normal to the axis of the balance.

The balance was mounted inside a styrofoam cylinder and the combined mass of the cylinder and moving portion of the balance were prevented from rotating by the strain-gauge beams. The natural frequency of oscillation was $32 \mathrm{~Hz}$. A much higher natural frequency without reduction in sensitivity could have been obtained if more rigid lead zirconate-titanate ceramic transducers had been used instead of strain-gauge beams. However, in the course of the investigation another method was suggested to $u s^{5}$ in which a special compensation circuit (see Fig. 3b) using analog computing techniques and operational amplifiers was used to remove the effects of the resonance at 32 $\mathrm{Hz}$.

To understand the compensation scheme we must consider the equation describing the response (output signal) $y(t)$ of the balance caused by the input torque $T(t)$ :

$$
\ddot{y}+\beta \dot{y}+\omega_{n}^{2} y=T(t)
$$

${ }^{5}$ We are indebted to Prof, E. G. Gilbert for the suggestion. 


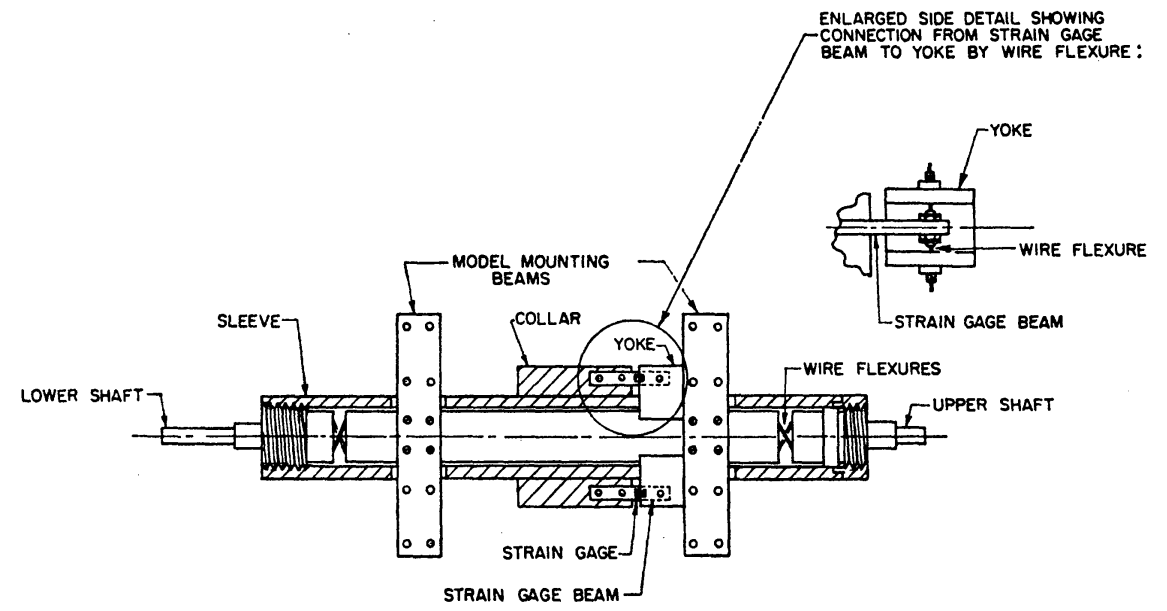

(a)

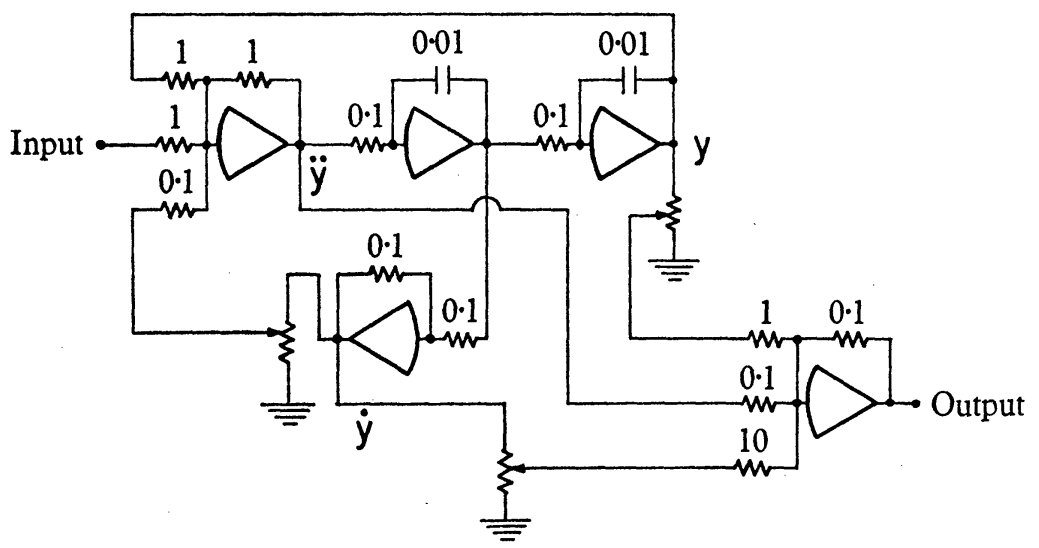

(b)

FiguRE 3. (a) Strain-gauge moment balance (Willmarth et al 1967).

(b) Analog compensation circuit for strain-gauge balance.

The damping $\beta$ and circular frequency $\omega_{n}$ were determined from an oscilloscope trace of the output signal produced by applying a step function (in torque) to the balance.

The compensation circuit, Figure $3 b$, produces an output signal that is approximately $T(t)$. The circuit consists of a second-order system (like Eq. 4, but with relatively large damping and a high resonant frequency, approximately $159 \mathrm{~Hz}$ ) using four amplifiers and a summing amplifier. The second-order system is used to produce signals in response to the balanceoutput signal that are reasonably accurate approximations to the terms $\ddot{y}$, $\dot{y}$, and $y$. The terms $\dot{y}$ and $y$ are each passed through potentiometers to obtain signals $\beta \dot{y}$ and $\omega_{n}^{2} y$. Next, the three terms $\ddot{y}, \beta \dot{y}$, and $\omega_{n}^{2} y$ are combined by means of the summing amplifier. The output signal of the summing amplifier 
is $T(t)$ (see Eq. 4). The compensation scheme was satisfactory up to frequencies of the order of $100 \mathrm{~Hz}$.

A novel torque transducer using optical principles and useful for stationary or rotating objects (without electrical connections to the rotating portion) has recently become available. ${ }^{6}$ The torque is applied to a shaft with a narrow neck, allowing it to twist. Two transparent disks are fastened to the shaft on either side of the narrow neck. The transparent disks are ruled with numerous pie-shaped, radially oriented, opaque regions. The applied torque causes a variation in the amount of light that can be transmitted normal to the disks. The light intensity is sensed by photo-conductive cells. The transducer output is relatively noise-free even when the shaft is rotated. It has been used as a torque meter in investigating autorotation of wings (Smith 1970).

3.4 Piezo-electric force balance.-The strain-gauge balance is extremely versatile and simple but in many cases suffers from rather low natural frequency when high sensitivity is required. In this case one should consider a change to piezo-electric force transducers instead of strain gauges.

A balance using piezo-electric transducers was used by Heller \& Widnall (1970) for measurements of high-frequency force fluctuations caused by air flow over rods, bars, and an airfoil. In Heller \& Widnall's transducer each end of the bar, rod, or airfoil was clamped against a pair of barium-titanate disks polarized in the thickness direction, assembled with the faces of like polarity adjacent to each other, and pressed on a common platinum-foil electrode between each pair of disks. The electrical signal was developed between the electrode and the outer faces of the disks. Biasing forces were applied by clamping set screws that pressed on rubber stoppers placed between the set screws and the ends of the bar, rod, or airfoil. The natural frequency of the transducer was limited by the first bending-mode frequencies of the bar, rod, or airfoil, which were 4500,4500 , and $1500 \mathrm{~Hz}$, respectively. The bar, rod, and airfoil were made from balsa wood with a steel rib and thin steel cover plates.

A two-component (lift and drag) version of the transducer was also reported but suffered from cross talk between the orthogonally positioned disks at the ends of the bar, rod, and airfoil. The cross talk (or interaction) was reduced to about 6 percent by pressing each pair of barium-titanate disks against a thin sheet of natural rubber .0045 inch thick. This provided for a small transverse restraint compared with the restraint normal to the disks. In this way both life- and drag-force fluctuations could be measured.

\section{General Comments on Measurements of Unsteady Pressures in a Flowing Fluid}

In addition to the problem of constructing or selecting a suitable transducer to measure fluctuating pressures, one must decide how to connect or

${ }^{6}$ Vibrac Corporation, Chelmsford, Mass. 
couple the pressure transducer to the fluid at the point in the flow field where the unsteady pressure is to be measured. When the pressure developed on an aerodynamic surface is to be measured, the simplest solution is to mount the transducer flush with the surface. This is a very satisfactory solution if the sensitive area of the transducer is considerably smaller than the spatial variation of the pressure along the surface. If the transducer area is not small enough (for example, when measuring wall-pressure fluctuations beneath thin turbulent boundary layers) one can partially correct for the error caused by finite transducer size (see Corcos 1963 and Willmarth \& Roos 1965). If the errors caused by poor spatial resolution are too large or unknown, one must measure the pressure after it is transmitted to the transducer through a small hole normal to the surface.

The error in the steady static pressure measured by a small hole in the surface has been studied more recently by Franklin \& Wallace (1970). They confirmed that the pressure in the hole is slightly higher than the true static pressure (the error is of the order of the wall shear stress when the hole diameter is of the order of 250 viscous lengths, $\nu \sqrt{\rho / \tau}$ ). The error in the unsteady pressure produced by measuring the pressure through a hole in a wall has not been studied experimentally. Fitzpatrick (1966) has deduced that for an inviscid fluid a small surface cavity is acoustically equivalent to a rigid transducer, flush with the surface, whose sensitivity varies over the surface in the same way as the normal efflux velocity that would result (at the actual hole in the wall) if a source were placed at the location of the transducer in the hole. His argument uses the reciprocity theorem of acoustics and does not consider the effects of fluid flow or viscosity. Remenyik (1962) has also done some work on a related problem (see section 5.5).

In addition to the unknown error produced by a static hole in the surface, there are time-lag errors caused by viscosity and inertia of the fluid trapped within the connections between the hole and transducer. Ducoffe (1953) has studied these effects for long capillary tubes connecting the static orifice and the transducer with response times ranging from $10^{-1}$ to $10^{2} \mathrm{sec}$ (very low frequencies). For best results at high frequencies one should naturally make the connection between the static hole and the transducer as short as possible with a very small volume of trapped fluid above the sensitive area of the transducer. At best, very little is known about the errors in unsteady pressure measurements that are caused by the connection of the transducer to a static hole in a plane surface when there is a fluid flowing over the surface.

Another more difficult problem is the measurement of impact- or staticpressure fluctuations in the flow away from solid boundaries. In this case the measurement of impact pressure presents less difficulty than that of static pressure. Gracey (1956), for example, showed that with a properly shaped entrance only small errors in impact pressure occurred at angles of attack as large as 20 degrees. In this case the design problem is to provide connections between the impact-pressure orifice and the transducer that will not 
seriously degrade the system response at high frequencies. Strasberg (1963) has reported successful measurements of the impact pressure in a turbulent wake using a commercially available capacitance microphone. The mass of air trapped in the tube leading to the microphone formed a Helmholtz resonator. The resonant-response peak occurred at 700 to $1000 \mathrm{~Hz}$ and was damped with a plug of cotton in the tube.

The measurement of fluctuating static pressure in the flow in the absence of solid boundaries is much more difficult than the measurement of impactpressure fluctuations, owing to the complicated interaction caused by the flow about the aerodynamic body (containing a static pressure orifice) that must be placed in the flow. ${ }^{7}$

Kistler (1961) has suggested an elaborate scheme to measure the turbulent pressure, requiring simultaneous measurements from hot wires and four piezo-electric pressure-sensitive elements. The piezo-electric elements measure the pressure on a cylinder aligned with the flow and provide vibration compensation. The hot wires are intended to sense the cross-flow velocity. No results of measurements using the scheme have been reported. Strasberg (1963) reported measurements of turbulent pressure fluctuations using a tube aligned with the flow containing an annular slit communicating the pressure to a microphone. Calibration of the unsteady static-pressure probe in the flow was not performed. A rather successful pressure-measurement and calibration reported by Siddon (1969) will be discussed in the next example.

\section{Selected Examples of Measurement Systems for Unsteady Pressures}

There are very many unsteady-pressure transducers available commercially. One can save a great deal of development time and money if a suitable commercial transducer can be selected. Minnar (1963) gives an extensive listing of commercially available pressure transducers. In the examples discussed below we consider instructive, advanced techniques not commercially available.

5.1 Fluctuating static pressure at a point in the flow.-Siddon (1969) has reported construction of an excellent probe for unsteady static-pressure measurements, and he has calibrated it in various contrived flows to remove the errors caused by the interaction of the body of the probe with streamwise and cross-flow velocity fluctuations. The general configuration of the probe is sketched in Figure 4. The pressure is transmitted to the diaphragm of a miniature condensor microphone (Siddon 1966) inside the probe through an annular slit approximately 2 diameters downstream from the ogive nose of the probe. A collar around the probe downstream of the slit was carefully positioned to make the steady pressure at the slit equal to the free-stream

${ }^{7}$ No discussion of methods not involving insertion of an orifice in the flow field will be given. None have been reported, to our knowledge. 


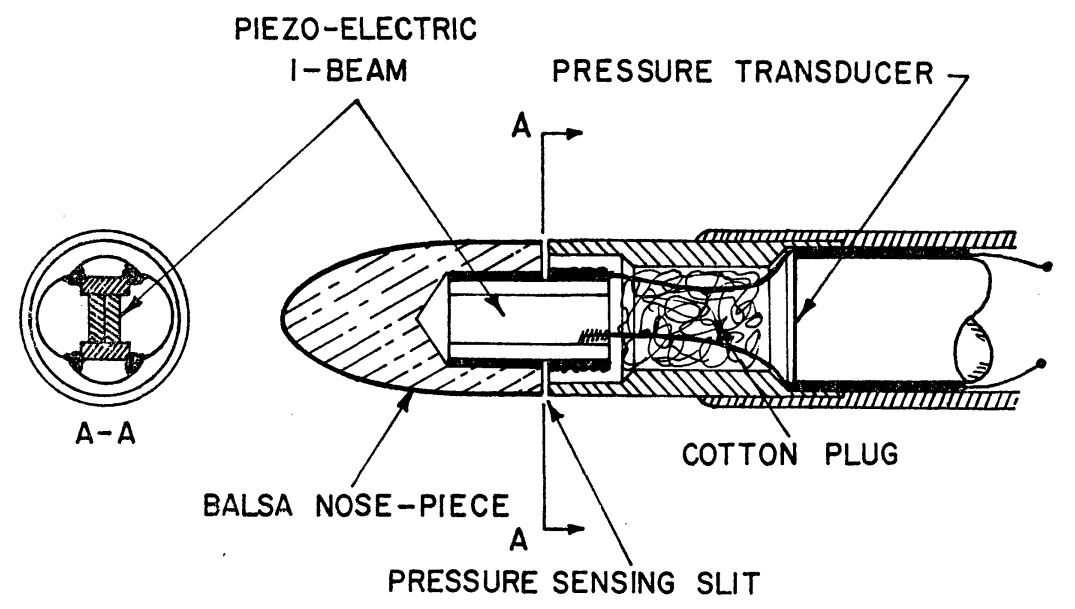

FIGURE 4. Fluctuating-static-pressure probe (Siddon 1969).

static pressure when there is no cross flow. The probe-collar compensation was checked at zero angle of attack in a flow with sinusoidal axial velocity fluctuations and was found adequate.

Siddon's unique achievement is the development of a compensation scheme to cancel the pressure fluctuations produced by cross-flow fluctuations. His scheme is based upon an earlier transducer (Siddon \& Ribner 1965) in which piezo-electric force-sensing elements were used to measure lift fluctuations of a small airfoil, which are proportional to velocity fluctuations normal to the airfoil when the angle-of-attack fluctuations are small. In the present case Siddon used an arrangement of four piezo-electric Bimorph plate elements in an I-beam configuration to measure the orthogonal bending moments produced by cross-flow-induced transverse forces on the nose of the probe. If quasi-steady, slender-body, aerodynamic theory is applicable, the transverse force will be proportional to the instantaneous transverse velocity at the nose. The two electrical signals representing the orthogonal components of transverse velocity were each squared and summed with analogcomputer elements to obtain a signal proportional to the square of the transverse velocity. A fraction of this signal was added to the pressure measured by the condensor microphone to give (approximately) the true static-pressure fluctuations that would have existed in the absence of the probe.

Siddon calibrated the probe in a flow produced by a jet of air passed through a rotating inclined nozzle. The probe slit was placed at the point where the static pressure is constant (the intersection of the nozzle axis and the axis of rotation). At that point any fluctuating pressure signals from the condensor microphone were assumed to be produced by cross-flow interaction with the probe. These signals were cancelled by addition of the properfraction of the square of the transverse velocity.

Siddon concluded that the error in the pressure produced by cross-flow 
interaction in turbulence was less than 20 percent. Thus, reasonably accurate measurements of fluctuating pressure could be made as long as the assumption of quasi-steady flow was not violated and the time lag between the transverse-force signal from the probe nose and the pressure measured at the annular slit was not important. Generally this requires that the spatial scale of the pressure fluctuations be much larger than the probe dimensions. As a result of his work Siddon was able to conclude that in many practical circumstances where only root-mean-square pressure fluctuations were measured with probes like Strasberg's (1963) (see section 4), the correction for cross-flow interaction is likely to be small. Owing to differences in the corrected and uncorrected wave forms one must use the corrected pressure when instantaneous values are desired, even when the corrected and uncorrected root-mean-square pressures are the same.

5.2 Small transducers for measuring transient or fluctuating pressure on a wall.- Recently Hofland \& Glick (1969) have, reported the construction of a miniature transducer of 5.1- $\mathrm{mm}$ diameter using lead zirconate-titanate disks. Their work is unique in that it represents, to the author's knowledge, the first paper describing a successful acceleration-compensation scheme for miniature piezo-electric pressure transducers. Their paper can be recommended to the reader because it gives an excellent account of the many considerations one must deal with in the successful development of piezo-electric pressure transducers.

Figure 5 is a sketch of the transducer of Hofland \& Glick (1969), which was assembled in a $\mathrm{Mu}$-metal cartridge used to isolate the transducer from transient magnetic fields produced during pressure measurements in a shock tunnel. Inside the cartridge are mounted two nearly identical lead zirconatetitanate disks each cemented to the cartridge, one behind the other, along a small area of their circumference. A small seismic mass is cemented to the

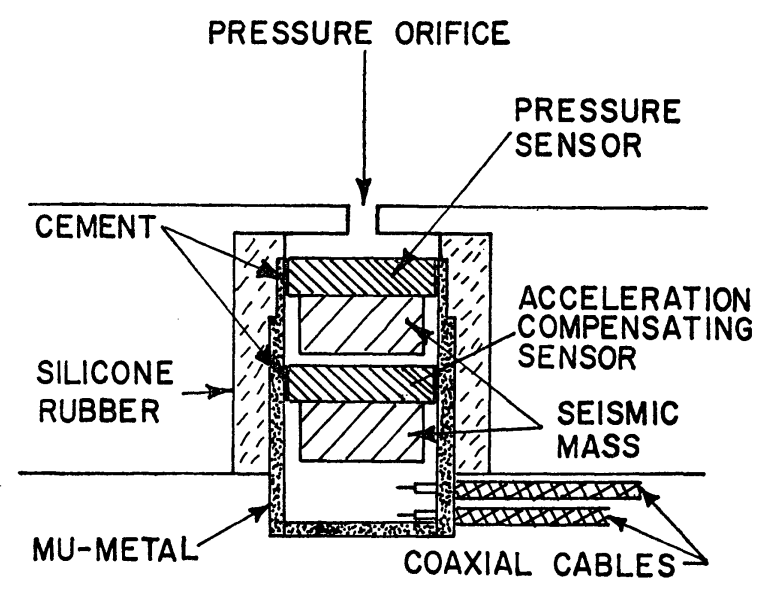

FIGURE 5. Miniature pressure transducer with acceleration compensation (Hofland \& Glick 1969). 
bottom face of each disk, but the top face of only the top disk is exposed to the pressure. The disks were carefully tested and matched for acceleration sensitivity as a function of frequency before mounting in the cartridge. The acceleration signal from the bottom disk (which is not exposed to the pressure) is subtracted from the signal from the top disk. Separate metal-oxide semiconductor field-effect transistors (MOSFET) with very high input impedance were mounted very near the transducer and used to amplify the small power signals from the piezo-electric transducers. Provisions for adjustable gain in each channel were made. The amount of acceleration signal from the bottom transducer, which was subtracted from the pressure-plusacceleration signal from the top transducer, could be adjusted to allow for changes in transducer sensitivity with time.

Hofland \& Glick calibrated their transducer in a shock tube. In fact, dynamic calibration is a necessity with ferro-electric transducers because they are subject to large irregular output-signal changes if one attempts to use a charge amplifier to obtain dc response for static calibration. The sensitivity of their transducer was $1.25 \mathrm{~V} / \mathrm{atm}$. The transducer was compensated for acceleration effects from 2 to $20,000 \mathrm{~Hz}$ Hofland \& Glick also carefully evaluated the transducer response to heat flux (pyroelectric effect) and found that a thin coating $(0.5 \mathrm{~mm})$ of silicone rubber on the gauge face was effective in preventing spurious signals caused by convective heating in their shock tunnel on a 10 degree cone model.

Smaller barium titanate and lead zirconate-titanate transducers flush with a wall, and with approximately the same sensitivity but without acceleration compensation, have been constructed by Clinch (1966), Kistler \& Chen (1963), Corcos (1962), Von Winkel (1961), Bull (1967), Willmarth (1958), and Willmarth \& Yang (1970). In all these transducers good vibration isolation was very important. The transducers constructed by Willmarth \& Yang (1970) were $1.52 \mathrm{~mm}$ in diameter with sensitivity of $1.35 \mathrm{~V} / \mathrm{atm}$. The frequency response was uniform to at least $50 \mathrm{kHz} .{ }^{8}$ The transducers were made from single disks mounted in small holes in a massive lead casting that was part of the aerodynamic surface. It was necessary to isolate the lead casting carefully from vibration when measuring turbulent fluctuations. To prevent convective-heating effects and to avoid leakage problems caused by the annular gap around the transducer disk, a thin rubber sheet in contact with the transducer face was stretched tightly over the surface.

5.3 Small piezo-electric pressure transducer with an acoustic absorbing rod.Ragland \& Cullen (1967) have reported construction and calibration of a $3.18-\mathrm{mm}$-diameter piezo-electric pressure transducer flush with the wall and mounted on an acoustic absorbing rod. Their design is based on similar trans-

\footnotetext{
${ }^{8}$ Willmarth (1958) has shown by shock-tube calibration that uniform frequency response to $50 \mathrm{kHz}$ is obtained from larger transducers, $4.1-\mathrm{mm}$ diameter, made in a similar manner.
} 
ducers reported by Edwards (1958) and Zaitsev (1958). The novel feature of the transducer is the utilization of an acoustic absorbing rod to prevent resonant oscillations and the accompanying oscillations of the output signal. These oscillations are particularly severe when the transducer is used to measure the rapid increase in pressure caused by a shock or detonation wave. The principle of the acoustic absorbing rod is based upon the fact that a plane longitudinal wave will not be reflected at the interface between two dissimilar materials if the acoustic impedance (the product of density and sound speed) is the same for each material. The transducer is made with a 3-mm-diameter, 0.5 -mm-thick lead metaniobate ${ }^{9}\left(\mathrm{PbNb}_{2} \mathrm{O}_{2}\right)$ disk that was soldered to the end of a $165-\mathrm{mm}-$ long rod of tin. The acoustic impedance of lead metaniobate and tin are nearly equal $\left(1.92 \times 10^{6}\right.$ and $1.99 \times 10^{6} \mathrm{~g} / \mathrm{cm}^{2} \mathrm{sec}$, respectively). The assembly of the tin rod and ceramic disk was positioned and "potted" in silicone rubber in a long brass housing with the disk poking out of a small hole flush with the end of the tube. The acoustic absorbing rod was effective in preventing reflected waves. In addition, the silicone rubber was also helpful in damping the waves as they passed along the tin rod. Only a very small signal was produced by the reflected wave from the end of the tin rod when the transducer was calibrated in a shock tube. The rise time of the transducer was better than $2.5 \mu \mathrm{sec}$, which was the shock transit time across the transducer face. The response to a normally incident shock was not checked. For normal incidence (in which submicrosecond rise time is desired), Baganoff (1964) has made an excellent pressure gauge, described below.

5.4 Pressure gauge for shock-reflection studies.-Baganoff (1964) has reported the successful development of a unique pressure transducer for measurements of the pressure profile on a wall during the reflection of a shock from the wall. The variation of capacitance between two electrodes, one on the gauge face and the other embedded within the gauge material .005 inch from the gauge face, is used to sense the applied pressure. The capacitor (100 pf) formed by the electrodes was charged to $4 \mathrm{kV}$ through a 60 -megohm resistor. Figure 6 is a sketch of the gauge, which was made from polycarbonate plastic. $^{10}$ When the gauge is exposed to a shock wave normal to the gauge face it is completely free from resonant oscillations during the time interval between shock arrival and the arrival at the inner electrode within the plastic of the first disturbance from the outer edge of the polycarbonate rod. For Baganoff's gauge the rise time was $0.1 \times 10^{-6} \mathrm{sec}$, and the useful test time was $5 \times 10^{-6} \mathrm{sec}$. After 5 microseconds the gauge output signal is useless owing to multiple reflections from the surfaces of the polycarbonate rod.

One can readily appreciate that this instrument is a very special-purpose device requiring uniform application of the pressure over the entire gauge

${ }^{9}$ A ferro-electric ceramic material commercially available from General Electric Corp.

${ }^{10}$ Lexan, General Electric Corp. 


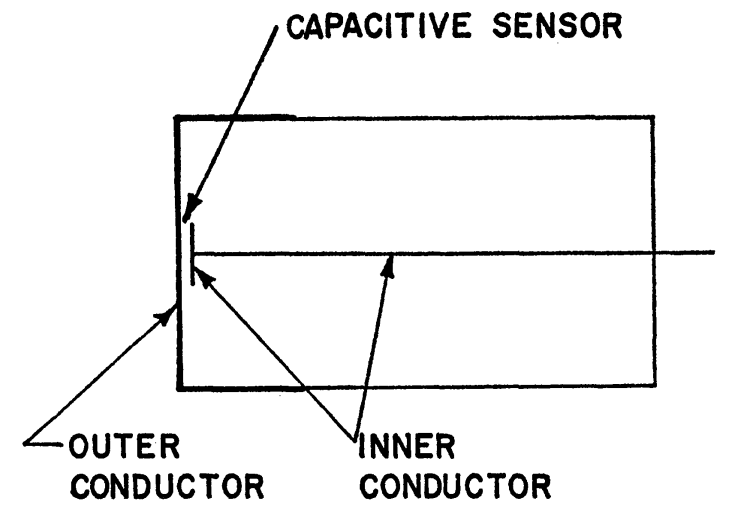

FIGURE 6. Pressure gauge with $\frac{1}{10}$ second rise time for shock-reflection studies (Baganoff 1964).

face. One must match the diameter of the gauge to the shock-wave curvature so that sufficiently uniform conditions over the gauge face are maintained. The construction of the inner electrode (which was formed from conductive epoxy and then covered with a thin disk of polycarbonate plastic) required very careful and uniform joining of the disk covering the inner electrode to the polycarbonate rod. The gauge sensitivity was approximately $.38 \mathrm{~V} / \mathrm{atm}$ with a $4-\mathrm{kV}$ bias voltage.

5.5 Miscellaneous pressure transducers for special applications.-Siddon (1966) has reported development of a miniature condensor microphone, 0.1 inch in diameter, which can be used to measure small pressure fluctuations to frequencies as high as $60 \mathrm{kHz}$. Condensor microphones of this size have recently become available commercially.

McDevitt, Harrison \& Lockman (1966) have reported measurements of pressure by FM telemetry using a capacitive pressure transducer (very similar to a condensor microphone) mounted inside a model in free flight in a wind tunnel. The nominal capacity of the transducer is $5 \mathrm{pf}$. Variations in capacity caused by pressure are used to frequency modulate a Colpitts common-emitter oscillator with a nominal frequency of $117 \mathrm{MHz}$. The signal radiated by the Colpitts oscillator is detected by an FM receiver whose antenna was mounted on the window of the wind tunnel.

Rindner \& Nelson (1962) have reported the development of a new class of semiconductor device that they call a piezo-junction, that can be used to construct a tiny pressure transducer. The pressure transducer uses a small diaphragm, which rests on a stylus pressing on the emitter junction of a transistor. The stress in the emitter junction controls the output across the collector junction. Outputs as high as $2 \mathrm{~V}$ rms were obtained from sound fields of 60 -db pressure amplitude (referred to $2 \times 10^{-4}$ dynes $/ \mathrm{cm}^{2}$ at zero db). Commercial versions of this type of transducer are available. ${ }^{11}$

$"$ Stow Laboratories Inc., Hudson, Mass. 
Massey \& Kavrak (1966) have constructed a very small pressure transducer made from a blob of conductive rubber. The rubber is mounted between a rigid and a flexible electrode and covered with a thin film of natural rubber that is used to insulate the conducting element from humidity changes that cause variable surface currents. The sensitivity was between 2 and $5 \mathrm{mV} / \mathrm{atm}$ depending upon the size and contact area of the rubber. The smallest transducer used a piece of rubber $1 \mathrm{~mm}$ in diameter and $\frac{1}{2} \mathrm{~mm}$ thick. The noise level was $.01 \mathrm{mV}$ rms.

Remenyik (1962) has reported development of an "Orifice Hot Wire" probe and has used it to measure pressure fluctuations beneath a compressible turbulent boundary layer. The orifice was a hole in the wall, $.84 \mathrm{~mm}$ in diameter, through which a low-speed bias flow was produced by suction to prevent nonlinear response of the hot wire, which was stretched across the hole $8.5 \mathrm{~mm}$ below the wall. The hole was continued without change in diameter in a $900-\mathrm{mm}$-long tube. The tube was long enough to damp reflected waves before they could return to the hot wire and mask the pressure signal. The sensitivity was $16 \mathrm{~V} / \mathrm{atm}$ and the transient response to a shock wave gave a rise time of $6 \times 10^{-5} \mathrm{sec}$. Remenyik performed approximate calculations that show that the fluctuating pressure at the hot wire inside the orifice is 20 percent less than the wall pressure outside.

Priestley (1965) has made a study of pressure fluctuations out-of-doors beneath the turbulent boundary layer developed on the ground. The pressures were measured with a pressure-sensitive capacitor that consisted of a thin metal diaphragm and backing plate mounted inside a capsule. The variations in capacitance caused by the variations in pressure were used to frequency modulate an electrical signal whose nominal frequency was 1550 $\mathrm{Hz}$. The frequency range of the pressure signals that Priestley studied was very low $(0.008 \mathrm{~Hz}$ to $1.0 \mathrm{~Hz})$. The entire data-recording and data-reduction system used digital-computer techniques, for which the frequency-modulated output signal from the variable-capacitance pressure transducer was admirably suited. The system is too complicated to allow a detailed description. The interested reader is advised to read Priestly's report.

\section{ACKNOWLEDGMENTS}

The author would like to thank E. O. Gilbert, E. G. Gilbert, and A. B. Macnee for their advice on the state of the electronic technology. The support of the Office of Naval Research under contract N00014-67-A-01810015 and the Army Research Office, Durham, under contract DAHCO-4$68 \mathrm{c}-0027$ is gratefully acknowledged.

\section{LITERATURE CITED}

Baganoff, D. 1964. Pressure Gauge with One-Tenth Microsecond Risetime for Shock Reflection Studies, Rev. Sci. Instrum. 35:288-95

Bull, M. K. 1967. Wall Pressure Fluctua-

tions Associated with Subsonic Turbulent Boundary Layer Flow, J. Fluid Mech. 28:719-54. Also see Univ. Southampton AASU Rep. No. 149, 1960 
Cady, W. G. 1946. Piezoelectricity. New York: McGraw-Hill

Clinch, J. M. 1966. Miniature Transducer Assembly for Measuring the Properties of the Wall-Pressure Field in Turbulent Flows, J. A coust. Soc. Am. 40:254-55

Corcos, G. M. 1963. Resolution of Pressure in Turbulence, J. Acoust. Soc. Am. $35: 192-99$

Corcos, G. M. 1962. Pressure Fluctuations in Shear Flows, Univ. California, Inst. Eng. Rep. No. 183

Dean, M., Douglas, R. D. 1962. Semiconductor and Conventional Strain Gages. New York: Academic

Ducoffe, A. L. 1953. Pressure Response in Supersonic Wind-Tunnel Pressure Instrumentation, J. Appl. Phys. $24: 1343-54$

Eastman, F. S. 1935. Flexure Pivots to Replace Knife Edges and Ball Bearings, Bull. No. 86 Eng. Exp. Sta. Univ. Washington

Edwards, D. H. 1958. A Piezo-electric Pressure Bar Gauge, J. Sci. Instrum. 35:346-49

Fitzpatrick, H. M. 1966. Spatial Resolution Effected by a Recessed Microphone, J. A coust. Soc. Am. 40:1247

Feynman, R. P. 1964. Lectures on Physics, Vol. II. Reading, Mass: AddisonWesley

Franklin, R. E., Wallace, J. M. 1970. Absolute Measurements of Static-Hole Error Using Flush Transducers, $J$. Fluid Mech. 42:33-48

Gracey, W. 1956. Wind-Tunnel Investigation of a Number of Total-Pressure Tubes at High Angle of Attack, NACA Tech. Note 3641

Heller, H. H., Widnall, S. E. 1970. Sound Radiation from Rigid Flow Spoilers Correlated with Fluctuating Forces, J. Acoust. Soc. Am. 47:924-36

Hofland, R., Glick, H. S. 1969. A Miniature Transducer for Measuring Low Transient Pressures, Rev. Sci. Instrum. 40:1146-51

Housner, G. W., Hudson, D. E. 1950. Applied Mechanics Dynamics. New York: Van Nostrand

Johnson, C. L. 1963. Analog Computer Techniques. New York: McGrawHill

Kistler, A. 1961. Piezo-electric Probe for Measurement of Static Pressure Fluctuations in Turbulent A ir Flow, J.P.L. Research Summary No. 36-7, 10-13

Kistler, A. L., Chen, W. S. 1963. A Fluctuating Pressure Field in a Super- sonic Turbulent Boundary Layer, J. Fluid Mech. 16:41-64

Lion, K. S. 1959. Instrumentation in Scientific Research. New York: McGrawHill

Massey, B. S., Kavrak, I. 1966. A Miniature Pressure Transducer, $J$. Sci. Instrum. 43:569-71

McDevitt, J. B., Harrison, D. R., Lockman, W. K. 1966. Measurement of Pressures and Heat Transfer by FM Telemetry, IEEE Trans. Aerosp. Electron. Syst. Vol AES-2, 2-12

Minnar, E. J., Ed. 1963. ISA Transducer Compendium. New York: Plenum Press

Morrison, C. F., Jr. 1964. A Primer in the Art of Using Operational Amplifiers in General Utility Instrumentation, Washington State Univ., Pullman

Neubert, H. K. P. 1963. Instrument Transducers. Oxford

Perry, C. C., Lissner, H. R. 1963. The Strain Gage Primer. New York: McGrawHill

Priestley, J. T. 1965. Correlation Studies of Pressure Fluctuations on the Ground Beneath a Turbulent Boundary Layer, Nat. Bur. Stds. Rep. 8942

Ragland, K. W., Cullen, R. E. 1967. Piezoelectric Pressure Transducer with Acoustic Absorbing Rod, Rev. Sci. Instrum. 38:740-42

Reichardt, H., Sattler, W. 1962. ThreeComponent-Measurements on Delta Wings with Cavitation, Final Rep. Max-Planck-Institut für Strömungsforschung, Göttingen

Remenyik, C. J. 1962. The "Orifice HotWire" Probe and its Application to Measurements of Pressure Fluctuations in a Compressible Turbulent Boundary Layer. Thesis. Dep. Mech. The Johns Hopkins Univ.

Rindner, W., Nelson, R. 1962. Piezo-Junctions: Elements of a New Class of Semiconductor Devices, Proc. IRE $50: 2106$

Roos, F. W., Willmarth, W. W. 1968. An Experimental Investigation of the Unsteady Flow About Spheres and Disks, Dep. Aerosp. Eng., Univ. of Michigan Rep. 01954-1-T

Routh, W. S., Eimbinder, J., Seymour, R., Brown, L., Krabbe, H. 1969. Designers Guide: Operational Amplifiers, EEE Mag. 57-78.

Siddon, T. E., Ribner, H. S. 1965. A Turbulence Probe Utilizing Aerodynamic Lift, J. AIAA 3:747-49 
Siddon, T. E. 1966. Devolopment of a Miniature Condensor Microphone, LingTemco-Vought Res. Cent. Western Div., T. R. No. 0-71200/6TR-106

Siddon, T. E. 1969. On the Response of Pressure Measuring Instrumentation in Unsteady Flow, Univ. Toronto Inst. Aerosp. Studies Rep. No. 136

Smith, E. H. 1970. Autorotating Wings: An Experimental Investigation, Dep. Aerosp. Eng., Univ. of Michigan Rep. 01954-2-T

Strasberg, M. 1963. Measurements of Fluctuating "Static" and Total-Head Pressure in a Turbulent Wake, NATO, AGARD Rep. 464

Von Winkle, W. A. 1961. Some Measurements of Longitudinal Space-Time Correlations of Wall Pressure Fluctuations in Turbulent Pipe Flow, U.S. Navy Underwater Sound Lab. Rep. No. 526

Willmarth, W. W. 1958. Small Barium Titanate Transducer for Aerody- namic or Acoustic Pressure Measurements, Rev. Sci. Instrum. 29. 218-22

Willmarth, W. W., Roos, F. W. 1965

Resolution and Structure of the Wall Pressure Field Beneath a Turbulent Boundary Layer, $J$. Fluid Mech. 22:1, 81-94

Willmarth, W. W., Hawk, N. E., Galloway, A. J., Roos, F. W. 1967. Aerodynamics of Oscillating Disks and a Right-Circular Cylinder, J. Fluid Mech. 27:1, 177-207

Willmarth, W. W, Enlow, R. 1969. Aerodynamic Lift and Moment Fluctuations of a Sphere, J. Fluid Mech. $36: 3,417-32$

Willmarth, W. W., Yang, C. S. 1970. WallPressure Fluctuations Beneath Turbulent Boundary Layers on a Flat Plate and a Cylinder, J. Fluid Mech. 41:47-80

Zaitsev, S. G. 1958. Measurement of Rapidly Varying Pressures in a Gas, Prib. Tekh. Eksp. 6:97 
Defense Documentation Center

Cameron Station

Alexandria, Virginia 22314

Technical Library

Naval Ship Research and Development Laboratory

Annapolis, Maryland 21402

Professor Bruce Johnson

Engineering Department

Naval Academy

Annapolis, Maryland 21402

Library

Naval Academy

Annapolis, Maryland 21402

Professor W. R. Debler

Department of Engineering Mechanics University of Michigan

Ann Arbor; Michigan 48108

Professor W. P. Graebel

Department of Engineering Mechanics

University of Michigan

College of Engineering

Ann Arbor, Michigan 48108

Professor Finn C. Michelsen

Naval Architecture and Marine

Engineering

445 West Engineering Building

University of Michigan

Ann Arbor, Michigan 48108

Dr. Francis Ogilvie

Department of Naval Architecture and Marine Engineering

University of Michigan

Ann Arbor, Michigan 48108

Professor W. W. Willmarth

Department of Aerospace Engineering

University of Michigan

Ann Arbor, Michigan 48108

National Science Foundation

Engineering Division

1800 G. Street, NW.

Washington, D.C. 20550
Dr. S.A. Piacsek

Argonne National Laboratory

Applied Mathematics Division

9700 S. Cass Avenue

Argonne, Illinois 60439

AFOSR (REM)

1400 Wilson Boulevard

Arlington, Virginia 22204

Professor S. Corrsin

Mechanics Department

The Johns Hopkins University

Baltimore, Maryland 20910

Professor I. S. G. Kovasznay

The Johns Hopkins University

Baltimore, Maryland 20910

Professor 0. M. Phillips

The Johns Hopkins University

Baltimore, Maryland 20910

Professor J. F. Kennedy, Director

Iowa Institute of Hydraulic Research

State University of Iowa

Iowa City, Iowa 52240

Librarian

Department of Naval Architecture

University of California

Berkeley, California 94720

Professor A. Thimuvengadam

Department of Mechanical Engineering

The Catholic University of America

Washington, D.C. 20017

Professor M. Holt

Division of Aeronautical Sciences

University of California

Berkeley, California 94720

Professor E. V. Laitone

Department of Mechanical Engineering

University of California

Berkeley, California 94720 
Professor P. Lieber

Department of Mechanical Engineering University of Califormia

Institute of Engineering Research

Berkeley, California 94720

Professor J. R. Paulling

Department of Naval Architecture

University of California

Berkeley, California 94720

Professor J. V. Wehausen

Department of Naval Architecture

University of California

Berkeley, California 94720

Professor E. R. van Driest

Virginia Polytechnic Institute and University

Department of Aerospace Engineering

Blacksburg, Virginia 24061

Commander

Boston Naval Shipyard

Boston, Massachusetts

02129

Director

Office of Naval Research Branch Office

495 Summer Street

Boston, Massachusetts 02210

Professor M. S. Uberoi

Department of Aeronautical Engineering

University of Colorado

Boulder, Colorado 80303

Commander

Puget Sound Naval Shipyard

Bremerton, Washington 98314

Professor J. J. Foody

Chairman, Engineering Department

State University of New York

Maritime College

Bronx, New York 10465

Dr. Alfred Ritter

Assistant Head, Applied Mechanics

Department

Cornell Aeronautical Laboratory, Inc.

Buffalo, New York 14221
Dr. A.S. Iberall, President

General Technical Services, Inc.

451 Penn Street

Yeadon, Pennsylvania 19050

Professor G. H. Carrier

Department of Engineering and Applied Physics

Harvard University

Cambridge, Massachusetts 02139

Professor G. Birkhoff

Department of Mathematics

Harvard University

Cambridge, Massachusetts 02138

Commanding Officer

NROTC Naval Administrative Unit

Massachusetts Institute of Technology

Cambridge, Massachusetts 02139

Professor M. A. Abkowitz

Department of Naval Architecture and Marine Engineering

Massachusetts Institute of Technology

Cambridge, Massachusetts 02139

Professor A. T. Ippen

Department of Civil Engineering

Massachusetts Institute of Technology

Cambridge, Massachusetts 02139

Professor I. N. Howard

Department of Mathematics

Massachusetts Institute of Technology

Cambridge, Massachusetts 02139

Professor E. W. Merrill

Department of Mathematics

Massachusetts Institute of Technology

Cambridge, Massachusetts 02139

Professor E. Mollo-Christensen

Room 54-1722

Massachusetts Institute of Technology

Cambridge, Massachusetts 02139

Professor N. Newman

Department of Naval Architecture and Marine Engineering

Massachusetts Institute of Technology

Cambridge, Nassachusetts 02139 
Professor A. H. Shapiro

Department of Mechanical Engineering

Massachusetts Institute of Technology

Cambridge, Massachusetts 02139

David M. Chase

Bolt, Beranek \& Newman, Inc.

50 Moulton Street

Cambridge, Massachusetts 02138

Commander

Charleston Naval Shipyard

U. S. Naval Base

Charleston, South Carolina 29408

A. R. Kuhl thai, Director

Research Laboratories for the Engineering Sciences

Thorton $\mathrm{Hall}$, University of Virginia

Charlottesville, Virginia 22903

Director

Office of Naval Research

Branch Office

536 South Clark Street

Chicago, Illinois 60605

Library

Naval Weapons Center.

China Lake, California 93555

Professor J. M. Burgers

Institute of Fluid Dynamics and Applied Mathematics

University of Maryland

College Park, Maryland 20742

Professor Pai

Institute for Fluid Dynamics and Applied Mathematics

University of Maryland

College Park, Maryland 20740

Acquisition Director

NASA Scientific \& Technical Information

P. 0. Box 33

College Park, Maryland 20740

Professor L. Landweber

Iowa Institute of Hydraulic Research State University of Iowa

Iowa City, Iowa 52240
Technical Library

Naval Weapons Laboratory

Dahlgren, Virginia 22448 .

Computation \& Analyses Laboratory

Naval Weapons Laboratory

Dahlgren, Virginia 22448

Dr. C. S. Wells, Jr.

Manager - Fluid Mechanics

Advanced Techrology Center, Inc.

P. 0. Box 6il4

Dallas, Texas 75222

Dr. R. H. Kraichnan

Dublin, New Hampshire 03444

Commanding Officer

Army Research Office

Box CM, Duke Station

Durham, North Carolina 27706

Professor A. Charnes

The Technological Institute

Northwestern University

Evanston, Illinois 60201

Dr. Martin H. Bloom

Polytechnic Institute of Brooklyn

Graduate Center, Dept. of Aerospace

Engineering and Applied Mechanics

Farmingdale, New York 11735

Technical Documents Center

Building 315

U. S. Army Mobility Equipment

Research and Development Center

Fort Belvoir, Virginia 22060

Professor J. E. Cermak

College of Engineering

Colorado State University

Ft. Collins, Colorado 80521

Technical Library

Webb Institute of Naval Architecture

Glen Cove, Long Island, New York 11542

Professor E. V. Lewis

Webb Institute of Naval Architecture

Glen Cove, Long Island, New York 11542 
Professor M. Poreh

Technion-Israel Institute of Technology

Haifa, Israel

Library MS 185

NASA, Langley Research Center

Iangley Station

Hampton, Virginia 23365

Dr. B. N. Pridmore Brown

Northrop Corporation

NORAIR-Div.

Hawthorre, California 90250

Dr. J. P. Breslin

Stevens Institute of Technology

Davidson Laboratory

Hoboken, New Jersey 07030

Dr. D. Savitsky

Stevens Institute of Technology

Davidson Laboratory

Hoboken, New Jersey 07030

Mr. C. H. Henry

Sterens Institute of Technology

Davidson Laboratory

Hoboken, New Jersey 07030

Dr. J. P. Craven

University of Hawaii

1801 University Avenue

Honolulu, Hawaii 96822

Professor E. L. Resler

Graduate School of

Aeronautical Engineering

Cornell University

Ithaca, New York 14851

Professor John Miles

\% I.G.P.P.

University of California, San Diego

La Jolla, California 92038

Director

Scrippe Institution of Oceanography

University of California

La Jolla, Califormia 92037

Dr. H. Cohen

IBM Research Center

P. 0. Box 218

Yorktown Heights, New York 10598
Professor A. Ellis

University of California, San Diego

Department of Aerospace \& Mech. Engrg. Sci.

La Jolla, California 92037

Dr. B. Sternlicht

Mechanical Technology Incorporated

968 Albany-Shaker Road

Latham, New York 12110

Ir. Coda Pan

Mechanical Technology Incorporated

968 Albany-Shaker Road

Latham, New York 12110

Mr. P. Eisenberg, President

Hydronautics, Inc.

Pindell School Road

Howard County

Laurel, Maryland 20810

Mr. M. P. Tulin

Hydronautics, Inc.

Pindell School Road

Howard County

Laurel, Maryland 20810

Mr. Alfonso Alcedan I. Director

Laboratorio Nacional De Hydraulics

Antigui Cameno A. Ancon

Casilla Jostal 682

Lima, Perv

Commander

Long Beach Naval Shipyard

Long Beach, California 90802

Professor John Laufer

Department of Aerospace Engineering

University Park

Los Angeles, California 90007

Professor J. M. Killen

St. Anthony Falls Hydraulic Lab.

University of Minnesota

Minneapolis, Minnesota 55414

Lorenz G. Straub Library

St. Anthony Falls Hydraulic Lab.

Mississippi River at Brd Avenue SE.

Minneapolis, Minnesota 55414

Chief of Research \& Development

Office of Chief of Staff

Department of the Army

The Pentagon, Washington, D.C. 20310 
Professor M. S. Plesset

Engineering Division

California Institute of Technology

Pasadena, California 91109

Professor A. Roshko

California Institute of Technology Graduate Aeronautical Laboratories

Pasadena, California 91109

Professor T. Y. Wu

Department of Engineering

Califomia Institute of Technology

Pasadena, California 91109

Director

Office of Naval Research

Branch Office

1030 E. Green Street

Pasadena, California 91101

Naval Ship Engineering Center

Philadelphia Division

Technical Library

Philadelphia, Pennsylvania 19112

Technical Library

Philadelphia Naval Shipyard

Philadelphia, Pennsylvania

Professor R. C. Mac Camy

Department of Mathematics

Carnegie Institute of Technology

Pittsburgh, Pennsylvania 15213

Dr. Paul Kaplan

Oceanics, Inc.

Plainview, Long Island, New York 11803

Technical Library

Naval Missile Center

Point Mugu, California 93441

Technical Library

Naval Civil Engineering Laboratory

Port Hueneme, California 93041

Commander

Portsmouth Naval Shipyard

Portsmouth, New Hampshire 03801

Commander

Norfolk Naval Shipyard

Portsmouth, Virginia 23709
Professor F. E. Bisshopp

Division of Engineering

Brown University

Providence, Rhode Island '02912

Dr. L. I. Higgins

TRW Space Technology Labs, Inc.

One Space Park

Redondo Beach, California 90278

Dr. William A. Gross, Vice President

Ampex Corporation

401 Broadway

Redwood City, Califomia 94063

Dr. H. N. Abramson

Southwest Research Institute

8500 Culebra Road

San Antonio, Texas 78228

\section{Editor}

Applied Mechanics Review

Southwest Research Institute

8500 Culebra Road

San Antonio, Texas 78206

Office of Naval Research

San Francisco Area Office

$50 \mathrm{Fell}$ Street

San Francisco, California 94102

Library

Pearl Harbor Naval Shipyard

Box 400

FPO San Francisco, California 96610

Technical Library

Hunters Point Naval Shipyard

San Francisco, California 94135

Librarian

Naval Ordnance Laboratory

White Oak

Silver Spring, Maryland 20910

Fenton Kennedy Document Library

The Johns Hopkins University

Applied Physics Laboratory

8621 Georgia Avenue

Silver Spring, Maryland 20910

Professor E. Y. Hsu

Department of Civil Engineering

Stanford University

Stanford, California 94305 
Professor J. Ripkin

St. Anthony Falls Hydraulic Lab. University of Minnesota

Minneapolis, Minnesota 55414

Dr. W. Silberman

St. Anthony Falls Hydraulic Lab. University of Minnesota

Minneapolis, Minnesota 55414

Superintendent

Naval Postgraduate School

Library Code 0212

Monterey, California 93940

Professor A. B. Metzner

University of Delaware

Newark, New Jersey 19711

Technical Library

Naval Underwater Systems Center

Newport, Rhode Island 02840

Professor Dudley D. Fuller

Department of Mechanical Engineering

Columbia University

New York, New York 10027

Professor V. Castelli

Department of Mechanical Engineering Columbia University

New York, New York 10027

Professor H. Elrod

Department of Mechanical Engineering

Columbia University

New York, New York 10027

Professor J. J. Stoker

Institute of Mathematical Sciences

New York University

251 Mercer Street

New York, New York 10003

Society of Naval Architects and

Marine Engineering

74 Trinity Place

New York, New York 10006

Engineering Societies Library

345 East 47 th Street

New York, New York 10017
Office of Naval Research

New York Area Office

207 W. 24th Street

New York, New York 10011.

Miss 0. M. Leach, Librarian

National Research Council

Aeronautical Library

Montreal Road

Ottawa 7, Canada

Professor A. K. Ray

Department of Applied Mechanics

University of Ottawa

Faculty of Pure \& Applied Science

Ottawa 2, Canada

Technical Library

Naval Ship Research and

Development Center

Panama City, Florida 32401

Technical Library

Naval Undersea R\&D Center

Pasadena Laboratory

3202 E. Foothill Boulevard

Pasadena, Califormia 91107

Dr. Andrew Fabula

Naval Undersea Research \& Development Center

Pasadena Laboratory

3202 E. Foothill Boulevard

Pasadena, California 91107

Dr. J. W. Hoyt

Naval Undersea R\&D Center

Pasadena Laboratory

3202 E. Foothill Boulevard

Pasadena, California 91107

Professor A. Acosta

Department of Mechanical Engineering

California Institute of Technology

Pasadena, California 91109

Professor H. Liepmann

Department of Aeronautics

California Institute of Technology

Pasadena, California 91109

Dr. G. Kulin

National Bureau of Standards

Washington, D.C. 20234 
Code 8040

Naval Research Laboratory

Washington, D.C. 20390

Code 031

Naval Ship Systems Command

Washington, D.C. 20390

Code 0341

Naval Ship Systems Command

Washington, D.C. 20390

Code 03412B (I. Benen)

Naval Ship Systerns Command

Washington, D.C. 20390

Code 03412 (J. Schuler)

Naval Ship Systems Command

Washington, D.C. 20390

Code 2052

Naval Ship Systems Command

Washington, D.C. 20390

Code 6034

Naval Ship Engineering Center

Center Building

Prince George's Center

Hyattsville, Maryland 20782

Code 6101E

Naval Ship Engineering Center

Center Building

Prince George's Center

Hyattsville, Maryland 20782

Code 6110

Naval Ship Engineering Center

Center Building

Prince George's Center

Hyattsville, Maryland 20782

Code 6113

Naval Ship Engineering Center

Center Building

Prince George's Center

Hyattsville, Maryland 20782

Code 6114

Naval Shjp Engineering Center

Center Building

Prince George's Center

Hyattsville, Maryland 20782
Code 6120E

Naval Ship Engineering Center

Center Building

Prince George's Center

Hyattsville, Maryland 20782

Code 6136

Naval Ship Engineering Center

Center Building

Prince George's Center

Hyattsville, Maryland 20782

Dr. A. Powell

Code 01

Naval Ship Research and Development Center

Washington, D.C. 20034

Mr. W. M. Ellsworth

Code $\mathrm{OH} 5 \mathrm{O}$

Naval Ship Research and Development Center

Washington, D.C. 20034

Central Library

Code 142

Naval Ship Research and Development Center

Washington, D.C. 20034

Dr. W. E. Cummins

Code 500

Naval Ship Research and Development Center

Washington, D.C. 20034

Mr. S. F. Crump

Code 513

Naval Ship Research and Development Center

Washington, D.C. 20034

Mr. R. Wermter

Code 520

Naval Ship Research and Development Center

Washington, D.C. 20034

Dr. P. Pien

Code 521

Naval Ship Research and Development Center

Washington, D.C. 20034 
Dr. Byrne Perry

Department of Civil Engineering

Stanford Universjty

Stanford, California 94305

Dr. R. I. Street

Departinent of Civil Engineering

Stanford University

Stanford, California 94305

Professor Militon Van Dyke

Department of Aercnautical Engineering

Stanford University

Stanford, California 94305

Professor S. Eskinazi

Department of Mechanical Engineering

Syracuse University

Syracuse, New York 1.3210

Professor R. Pfeffer

Florida State University

Geophysical Fluj.d Dynamics Institute

Tallahassee, Florida 32306

Professor R. C。Di Prima

Department of Mathematics

Rensselaer Polytechnic Institute

Troy, New York 12180

Dr. Lee Segel

Department of Mathematics

Rensselzer Polytechnic Institute

Troy, New York 12180

Professor J. Lumley

Ordnance Research Laboratory

Pennsylvania State University

University Park, Pennsylvania

16801

Dr. M. Sevik

Ordnance Research Laboratory

Pennsylvania State University

University Park, Pennsylvania

16801

Dr. J.M. Robertson

Department of Theoretical and Applied Mechanics

University of Illinois

Urbana, Illinois 61803

Technical Library

Mare Is]and Naval Shipyard

Vallejo, Califormia 94592
Code 438

Office of Naval Research

Department of the Navy

Arlington, Virginia 22217

(3)

Code $46 \mathrm{l}$

Office of Naval Research

Department of the Navy

Arlington, Virginia 22217

Science \& Technology Division

Library of Congress

Washington, D.C. 20540

Department of the Army

Coastal Engineering Research Center

5201 Little Falls Road, NW.

Washington, D.C. 20011

Code 4.68

Office of Naval Research

Depariment of the Navy

Arlington, Virginia 22217

Code 473

Office of Laval Research

Department of the Navy

Arlington, Virginia 22217

Code 481

Office of Naval Research

Depertment of the Navy

Arlington, Virginia 22217

Code 2627

Naval Fesearch Laboratory

Washington, D。C, 20390

Library, Code 2620 (ONRL)

Naval Research Laboratory

Washington, D.C. 20390

Code 6170

Naval Research Laboratory

Washington, D.C. 20390

Code 4000

Director of Research

Naval Research Laboratory

Washington, D.C。 20390

Code 8030 (Maury Center)

Naval Research Laboratory

Weshington, D.C. 20390 
Dr. W. B. Morgan

Code 540

Naval Ship Research and Devel opment Center

Washington, D.C. 20034

Mr. P. Granville

Code 541

Naval Ship Research and Development Center

Washington, D.C. 20034

Mrr. J. B. Hadler

Code 560

Naval Ship Research and Development Center

Washington, D.C. 20034

Dr. H. R. Chaplin

Code 600

Naval Ship Research and Development Center

Washington, D.C. 20034

Mr. G. H. Gleissner

Code 800

Naval Ship Research and Development Center

Washington, D.C. 20034

Dr. M. Strasberg

Code 901

Naval Ship Research and Development Center

Washington, D.C. 20034

Mr. J. McCarthy

Code 552

Naval Ship Research and Development Center

Washington, D.C. 20034

Code 03

Naval Air Systems Command

Washington, D.C. 20360

AIR 5301

Naval Air Systems Command

Department of the Navy

Washington, D.C. 20360

AIR 604

Naval Air Systems Command

Department of the Navy

Washington, D.C. 20360
Code ORD 03

Naval Ordnance Systems Command

Washington, D.C. 20360

Code ORD 035

Naval Ordnance Systems Command

Washington, D.C. 20360

Code ORD 05413

Naval Ordnance Systems Command

Washington, D.C. 20360

Code ORD 9132

Naval Ordnance Systems Command

Washington, D.C. 20360

Oceanographer of the Navy

Washington, D.C. 20390

Commander

Naval Oceanographic Office

Washington, D.C. 20390

Chief Scientist (CNM PM-1)

Strategic Systems Project Office

Department of the Navy

Washington, D.C. 20360

Technical Division (CNM PM 11-20)

Deep Submergence Systems Project Office

Department of the Navy

Washington, D.C. 20360

Dr. A. I. Slafkosky

Scientific Advisor

Cormandant of the Marine Corps (Code AX)

Washington, D.C. 20380

Librarian Station 5-2

Coast Guard Headquarters

NASSIF Building

4007 th Street, S.W.

Washington, D.C. 20591

Office of Research and Development

Maritime Administration

441 G. Street, NW.

Washington, D.C. 20235

Division of Ship Design

Maritime Administration

441 G. Street, NW.

Washington, D.C. 20235 

DOCMENT CONTROL DATA - R Q D

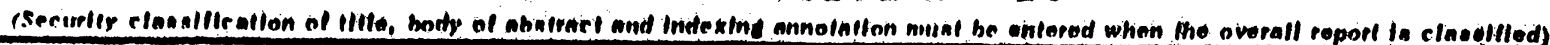
- QRIOINA TINO Activitr (Comoraio nuthor)

The University of Michigan

Department of Aerospace Engineering

Ann Arbor, Michigan

20. REPORT SECURITY CLASSIFICATION Unclassified

2b. GROUP

3. MEMONT TITLE

Unsteady Force and Pressure Measurements 8006

4. DEschip tive nOtes (Typo of reporl and Inclunive dalea)

Reprint

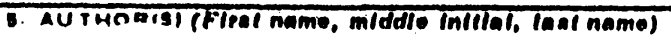

William W. Willmarth

\begin{tabular}{|c|c|c|}
\hline $\begin{array}{l}\text { D. AEOAT OAT } \\
\text { September } 1971\end{array}$ & $\begin{array}{l}\text { 79. TOTAL NO. OF PAOES } \\
24\end{array}$ & $\begin{array}{l}\text { 76. NO. OF REFS } \\
46\end{array}$ \\
\hline $\begin{array}{l}\text { 8. CRNTAACT OR GAANT NO. } \\
\text { NOOO14-67-A-0181-0015 } \\
\text { b. PROJECT NO. }\end{array}$ & \multicolumn{2}{|c|}{$\begin{array}{l}\text { 9a. ORIGINATOR'S REPORT NUMBERISI } \\
\qquad 021490-2-T\end{array}$} \\
\hline $\begin{array}{l}\text { c. } \mathrm{NR} 062-234 \\
\text { d. }\end{array}$ & \multicolumn{2}{|c|}{ 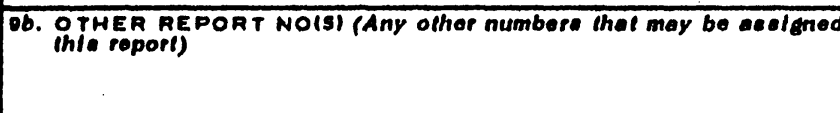 } \\
\hline
\end{tabular}

10. DISTAIOUTION STATEMENT

Approved for public release; distribution unlimited.

\begin{tabular}{|l|l|}
\hline 11. SUPPLEMENTAAY NOTES & $\begin{array}{l}\text { 12. SPONSORING MILITARY ACTIVITY } \\
\text { Office of Naval Research, Code } 438 \\
\text { Department of the Navy } \\
\text { Arlington, Virginia } 22217\end{array}$ \\
\hline
\end{tabular}

A review and survey of solutions to problems of unsteady force and pressure measurements. The survey covers general principles of design of measurement systems. Selected illustrative examples of existing systems that are relatively sophisticated are presented. Ordinary measurement problems that can be solved with commerically avallable transducers are not included in the examples. 


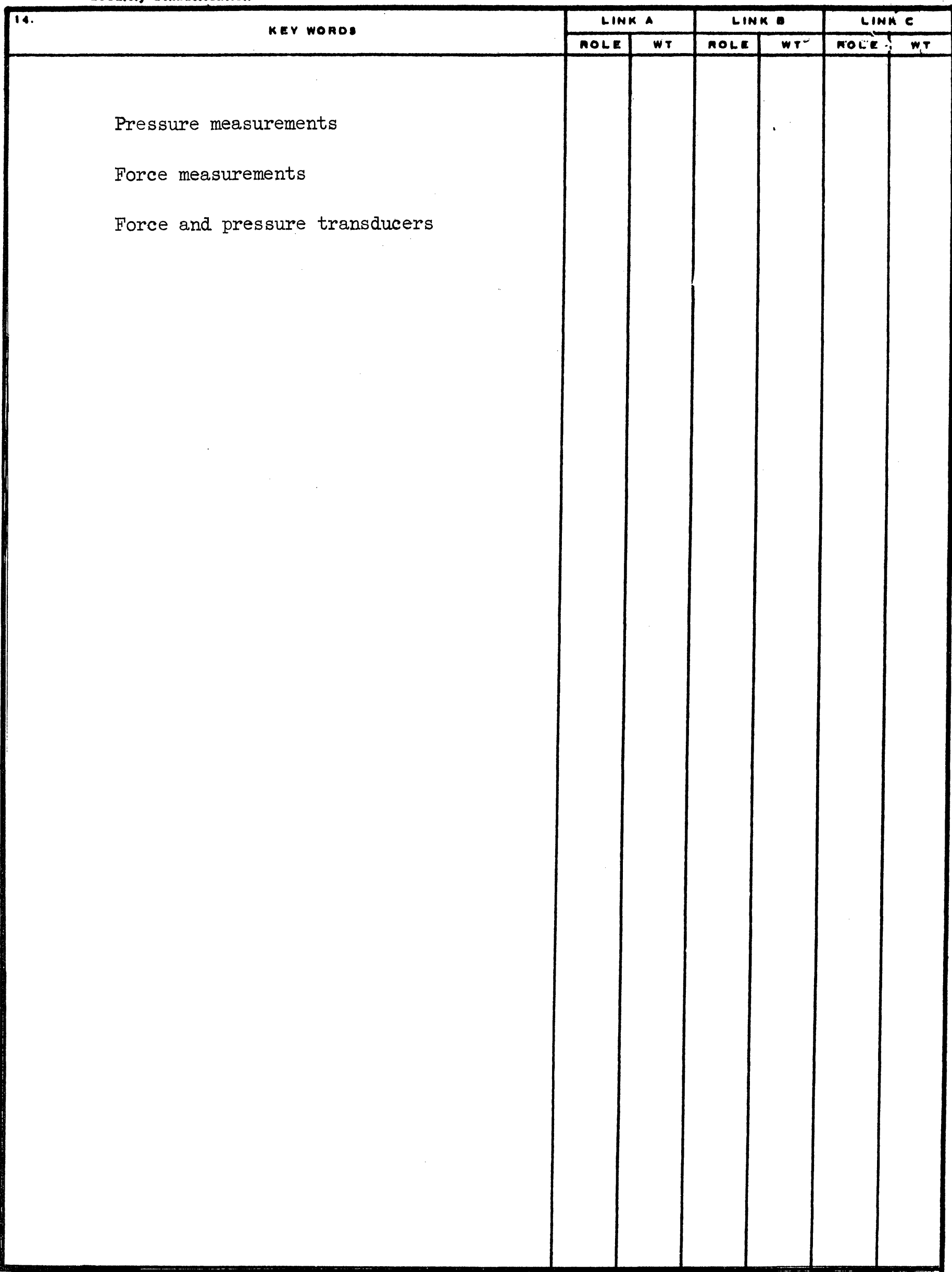



39015035275760 